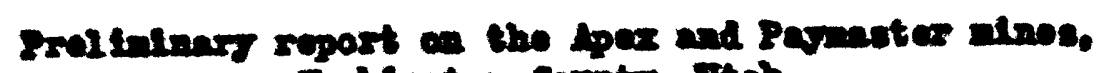

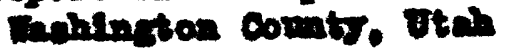

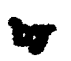

4. 2. Itinal. Is.

This roport and accompaning illustrations aro preliminary and have not been edited or reviewed for conformity with U. S. Geological Survey atandards and nomenclature.

$5 \mid-1$

Public Inquaries cifico

U.S. Geolcelcai Stirvey

Ru 8105 Feceral H1ag

125 South Stzte Street

Salt Iake C $=t y$, Utah 84138 


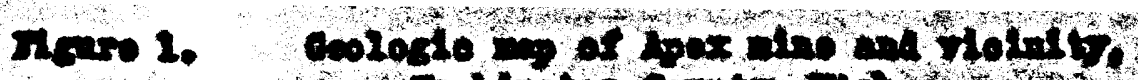

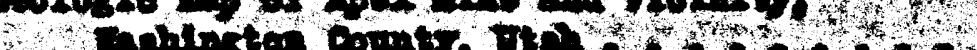

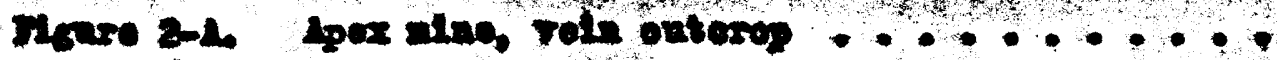

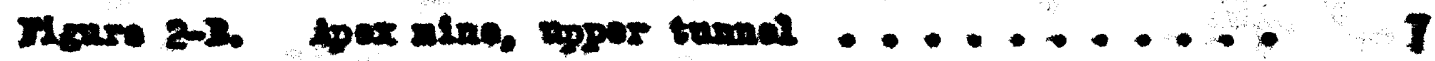

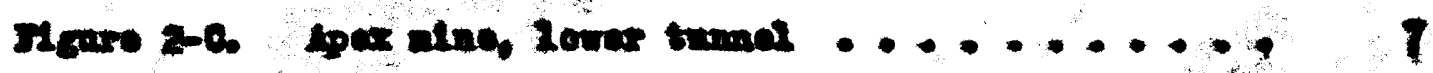

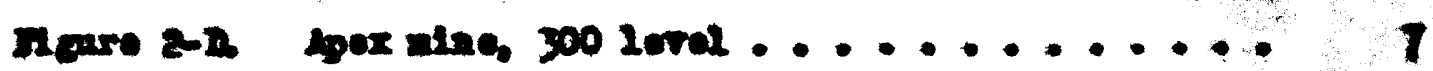

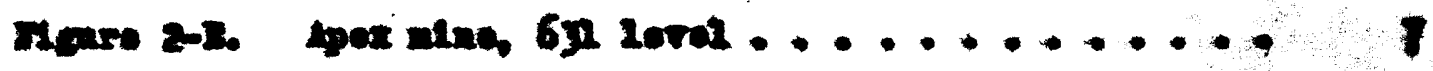

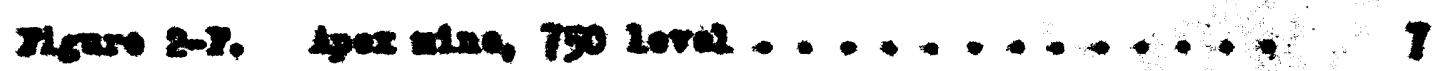

Thare 2-6, 4pox mino; 900 lotel ............. 1

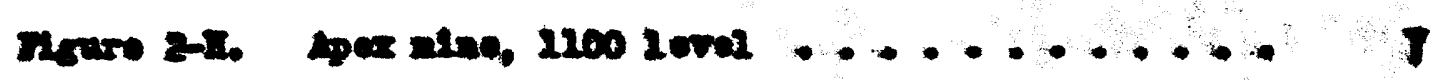

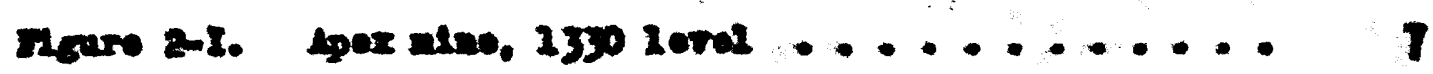

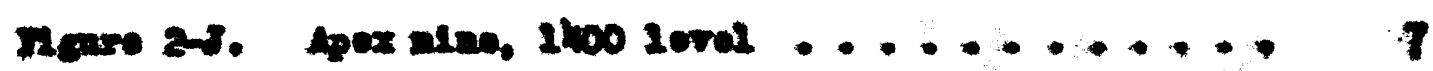

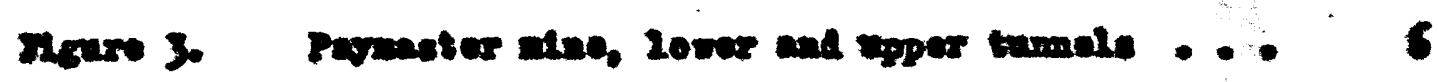

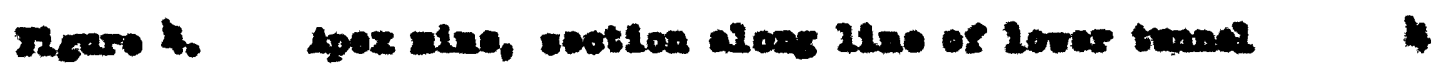




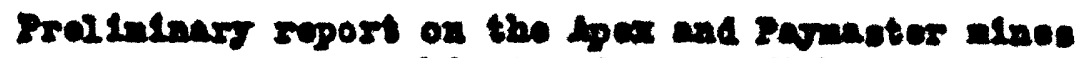
wabingten comty. Vter

$$
\begin{aligned}
& 7 . \\
& \text { A no dator, 7ro } \\
& \text { stober } 19 \\
& \text { Dotrent }
\end{aligned}
$$

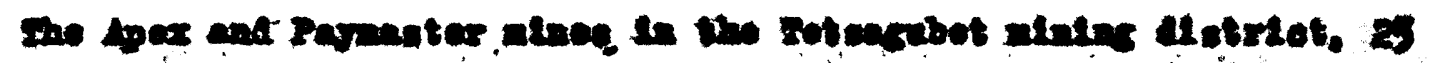

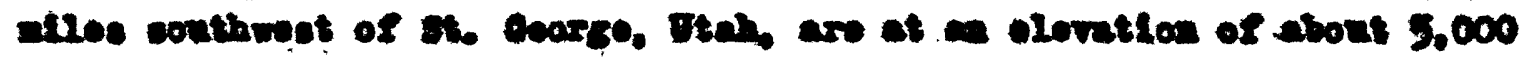

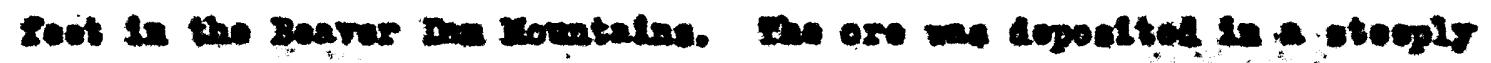

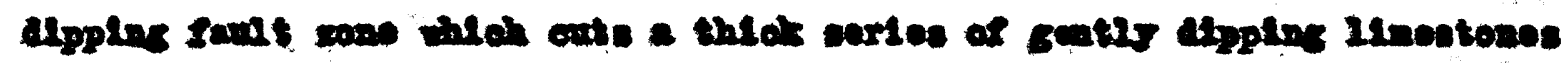

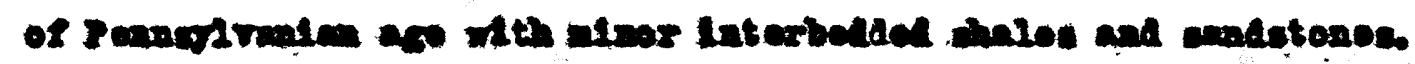

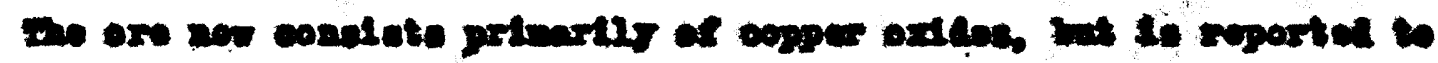

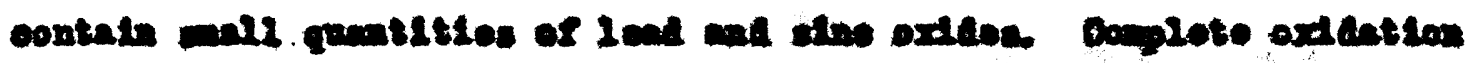

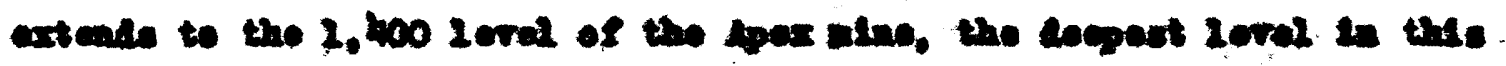

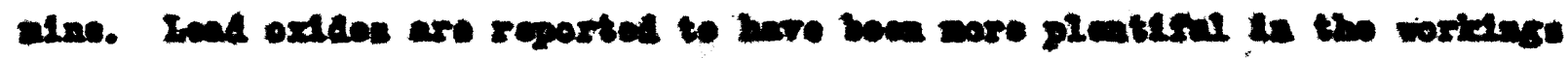

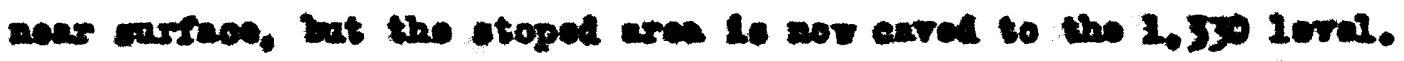

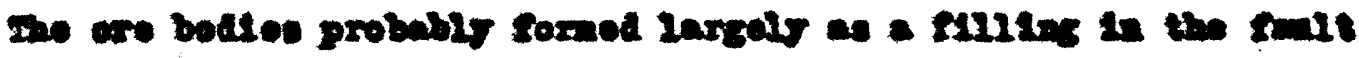

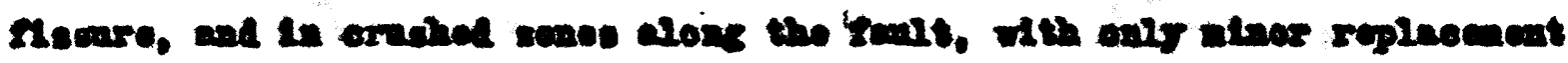

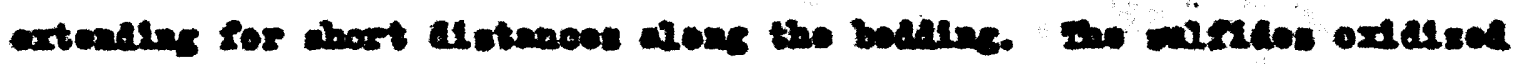

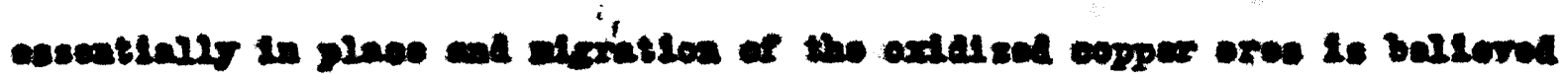

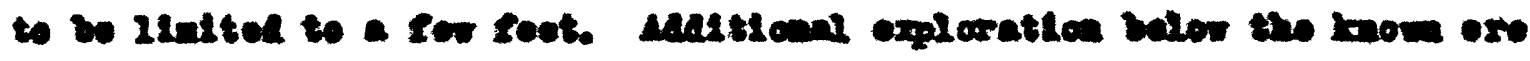

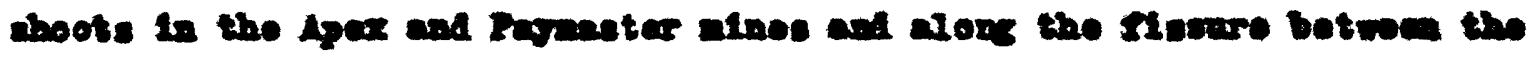

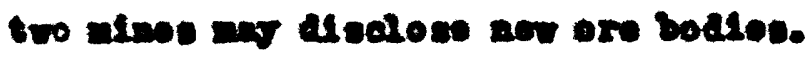




\section{Introduct 202}

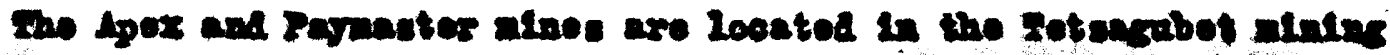

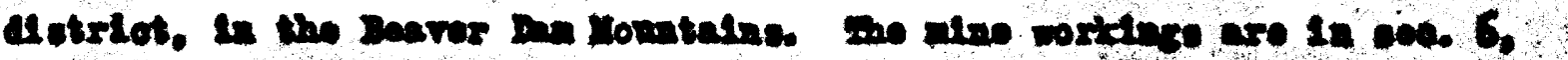

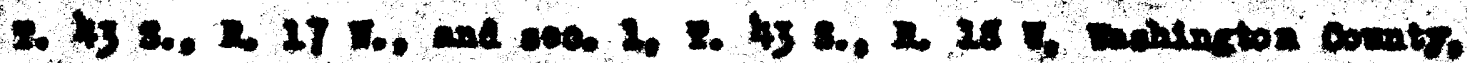

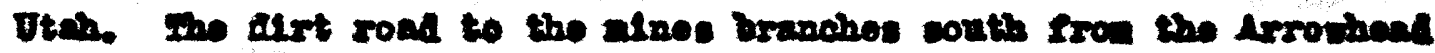

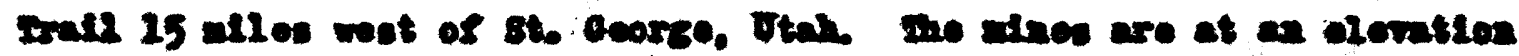

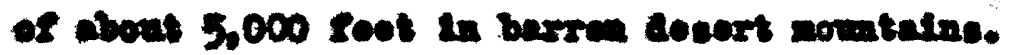

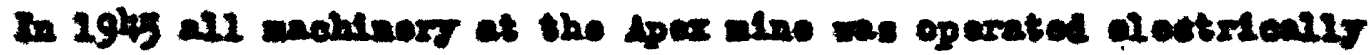

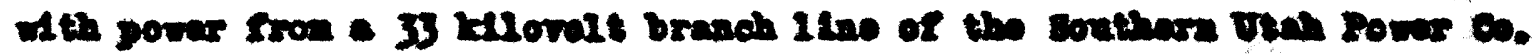

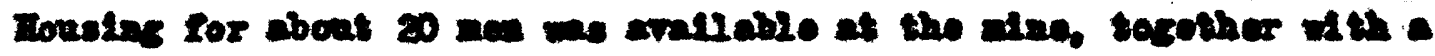

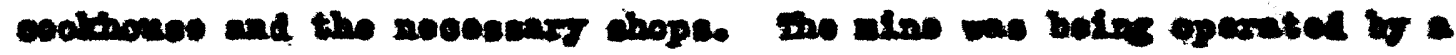

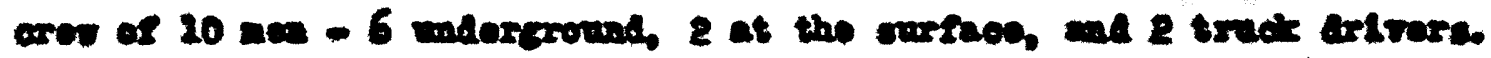

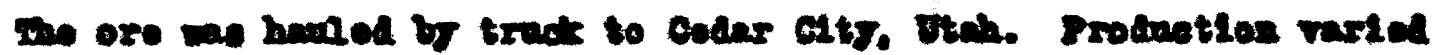

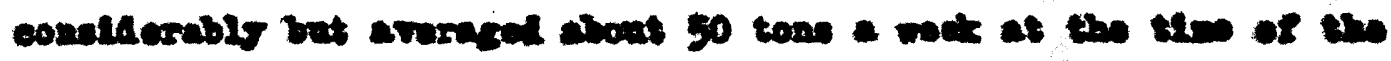

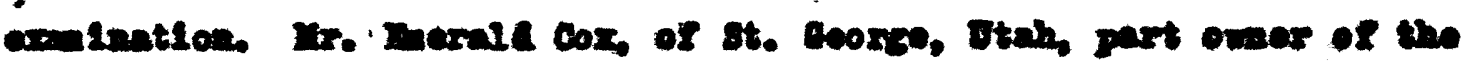

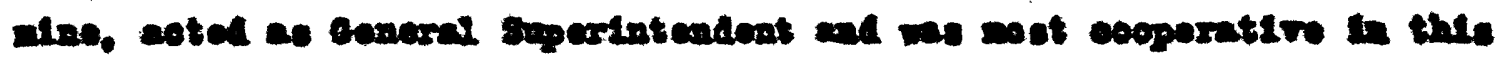
inrootigation.

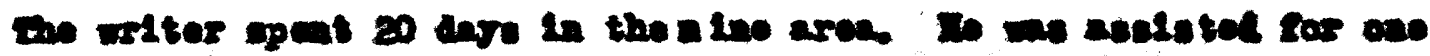

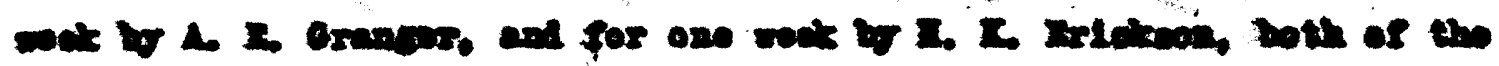
consocied surnot. 


\section{Antory}

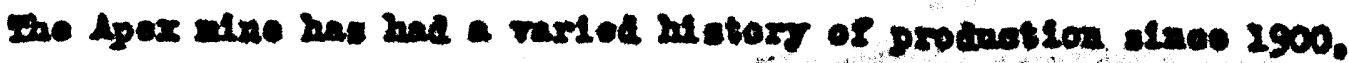

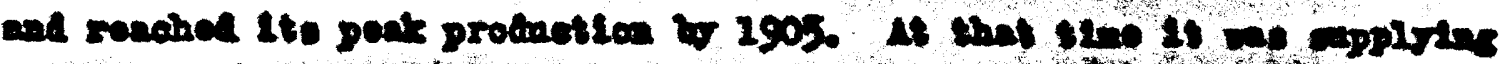

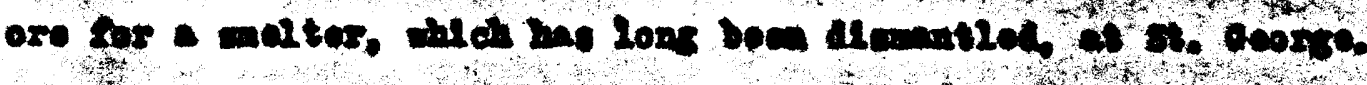

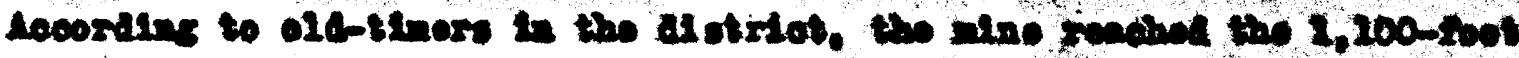

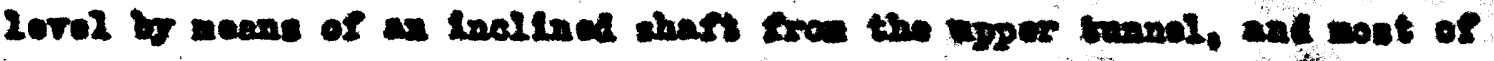

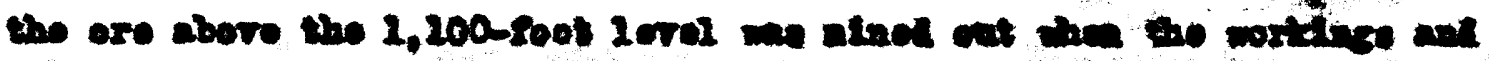

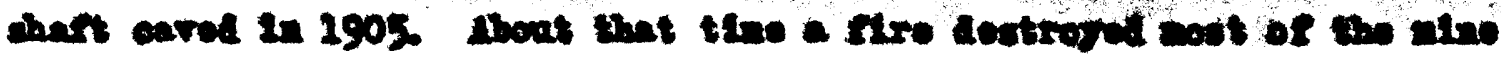

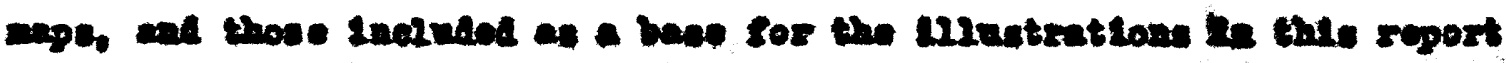

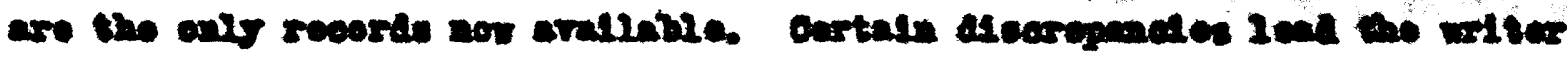

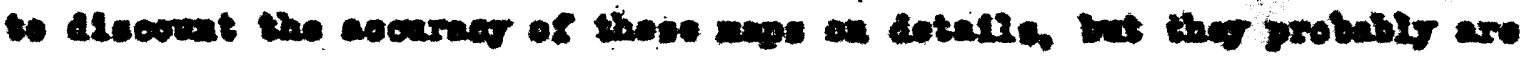

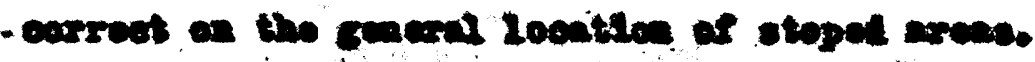

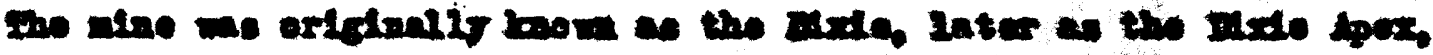

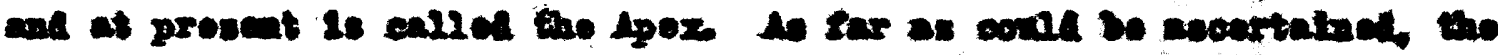

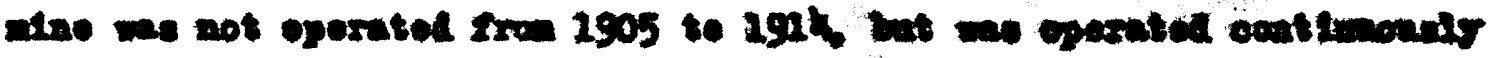

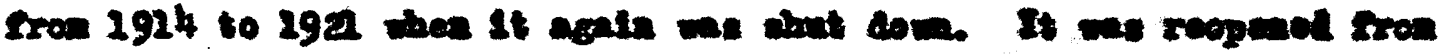

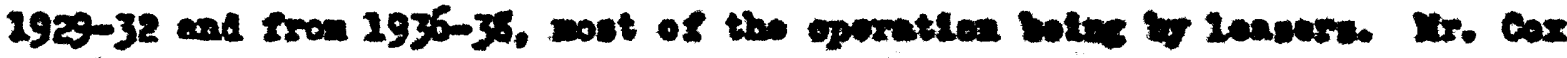

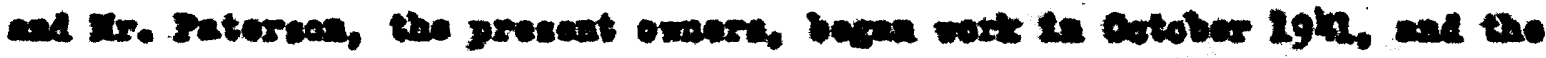

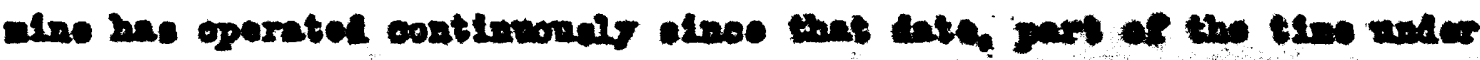

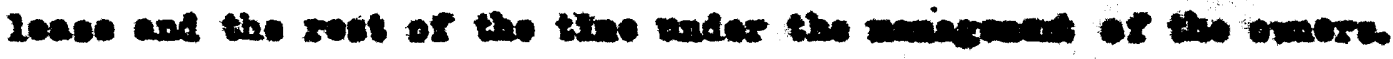

\section{omlog}

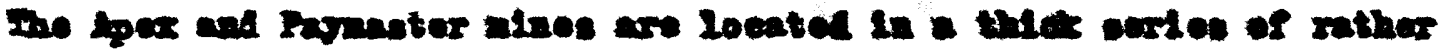

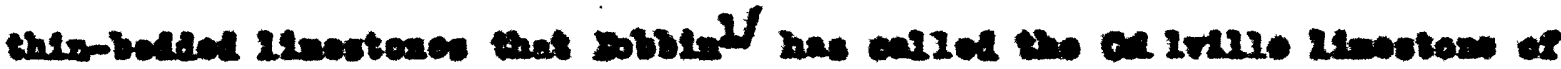

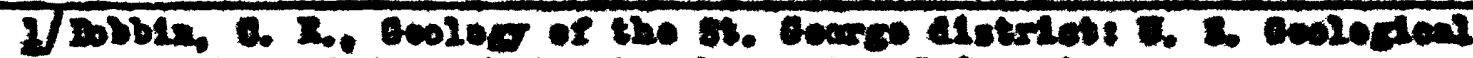

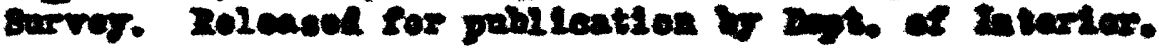

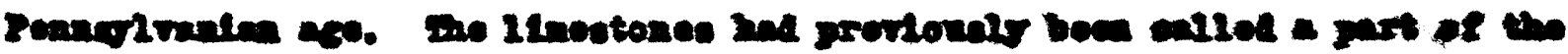




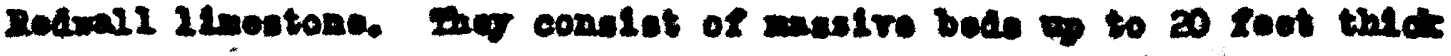

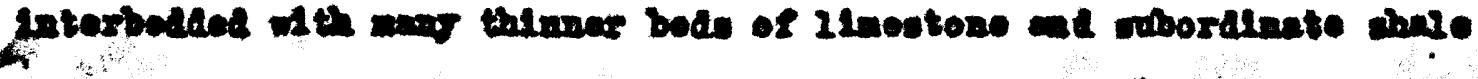

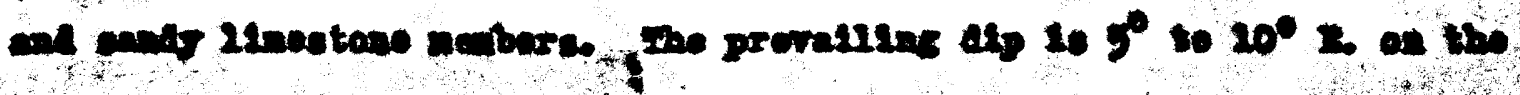

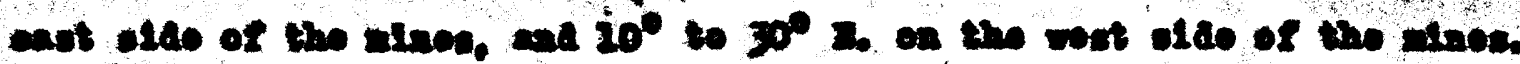

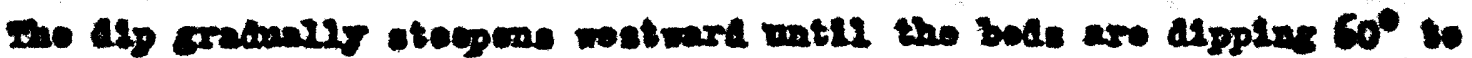

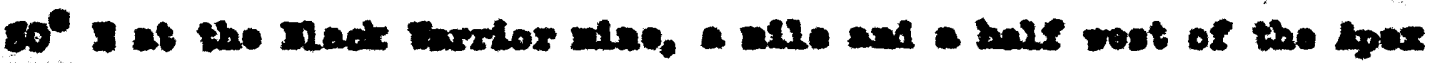

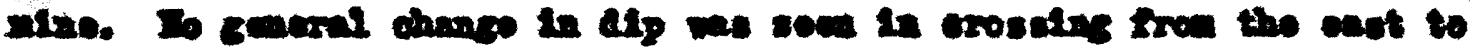

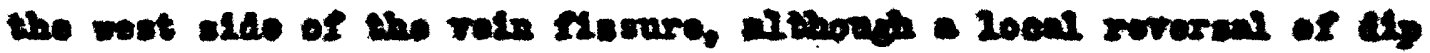

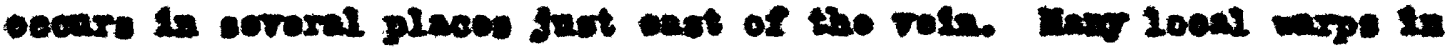

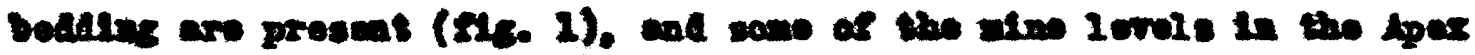
Dat.

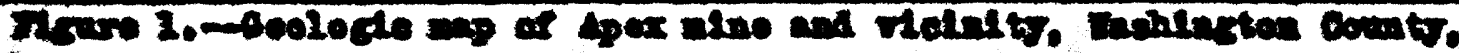

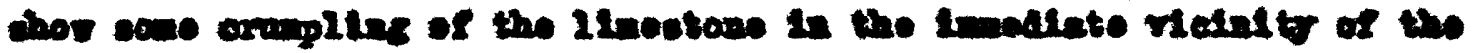

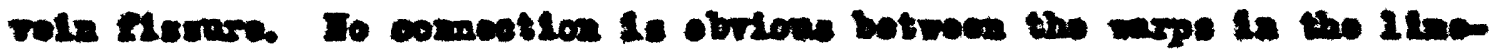

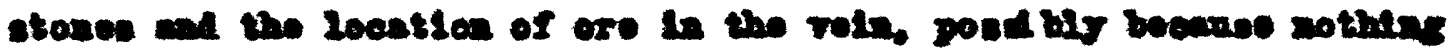

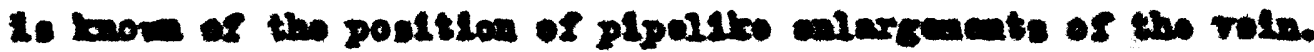

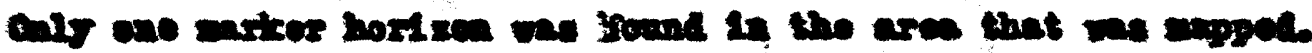

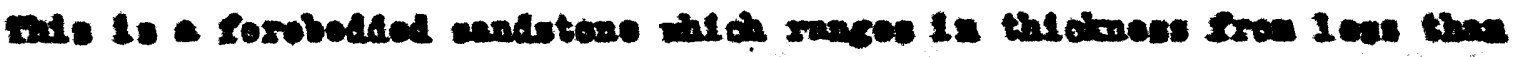

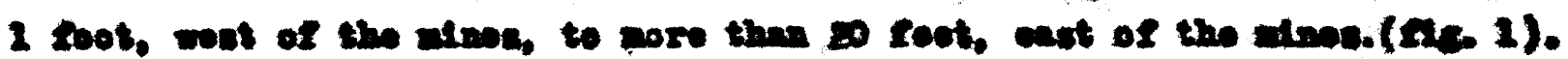

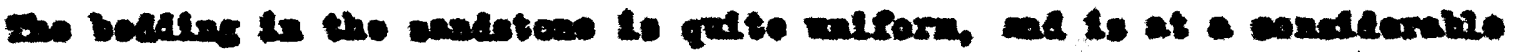

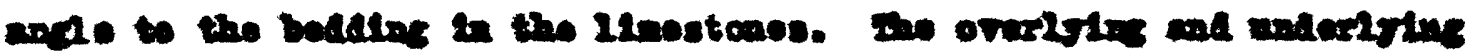

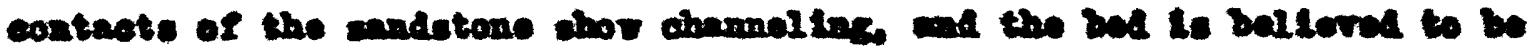

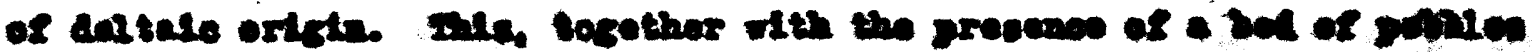

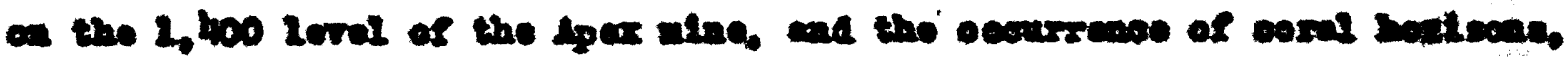

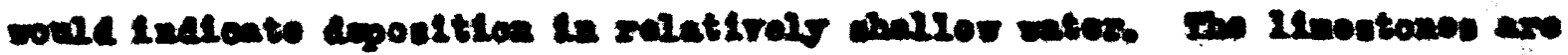

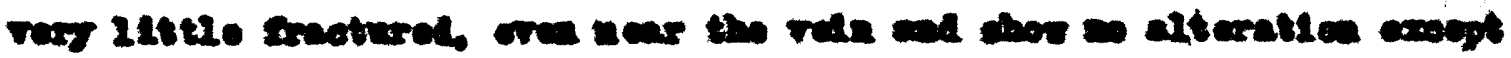

$$
-40
$$




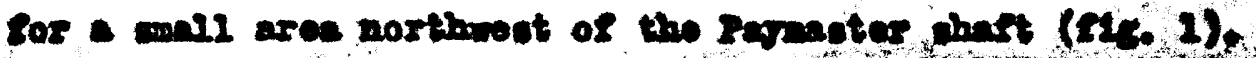

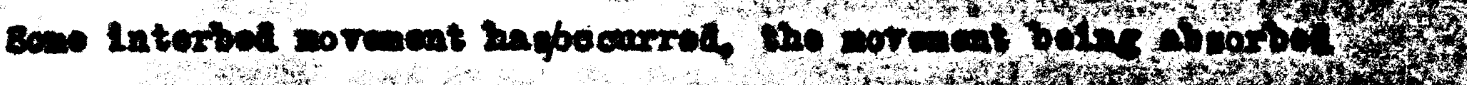

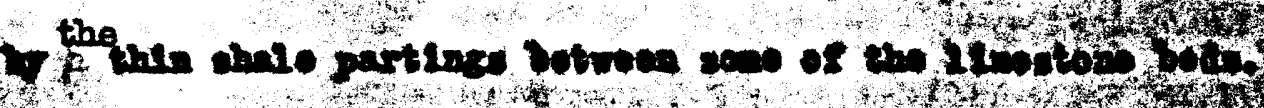

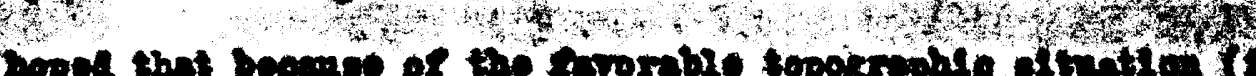

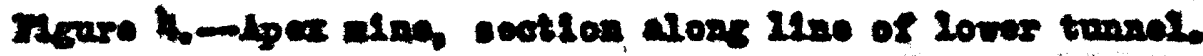

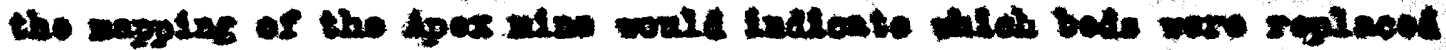

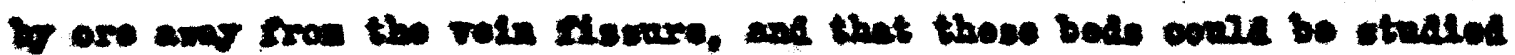

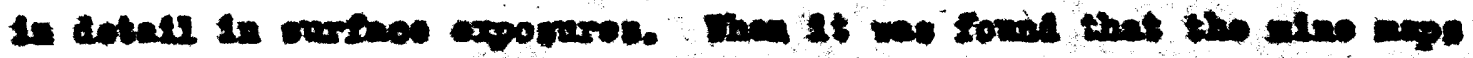

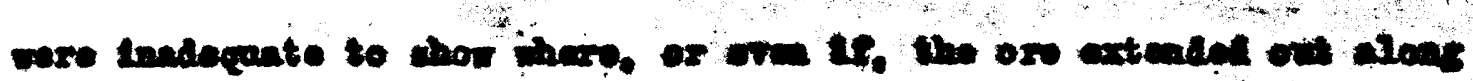

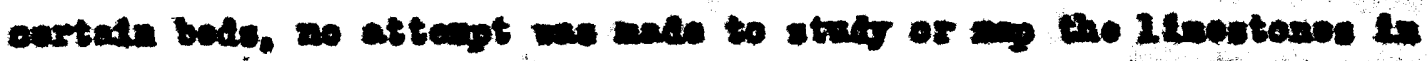
atall.

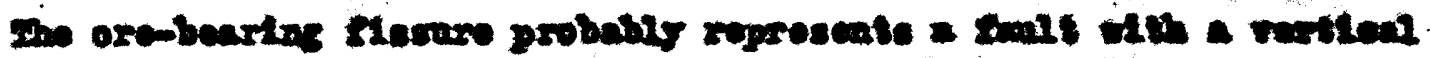

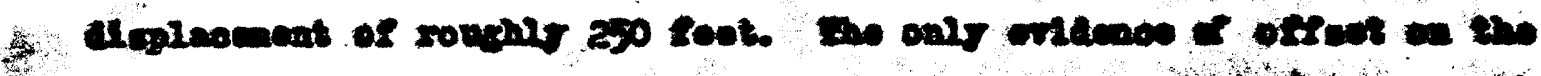

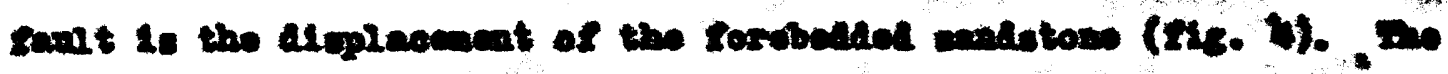

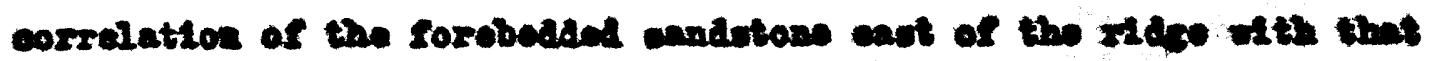

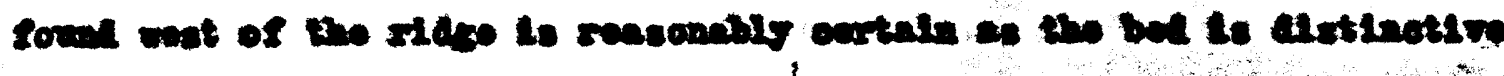

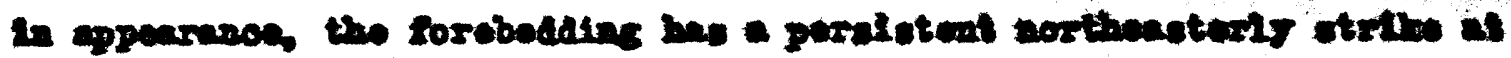

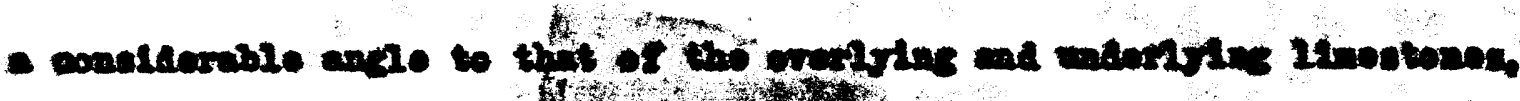

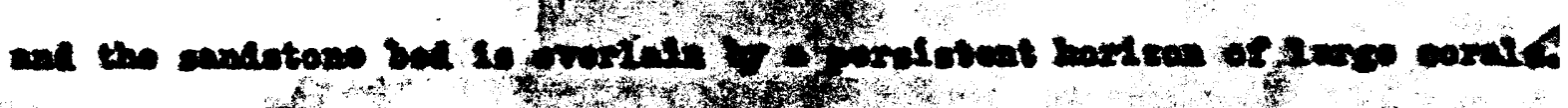

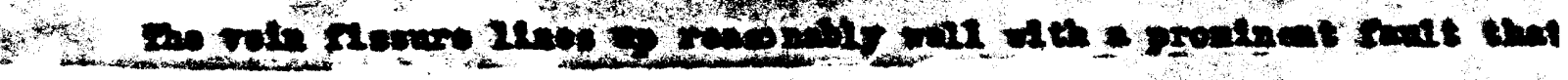

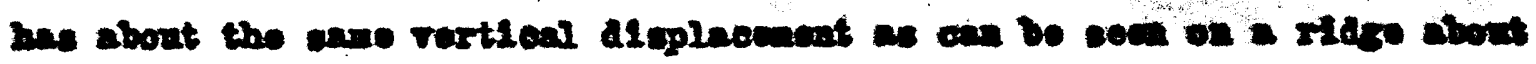

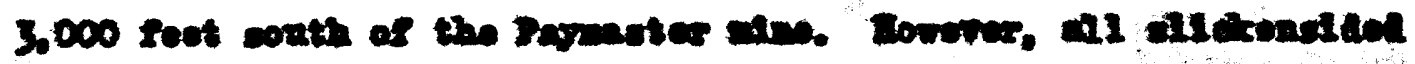

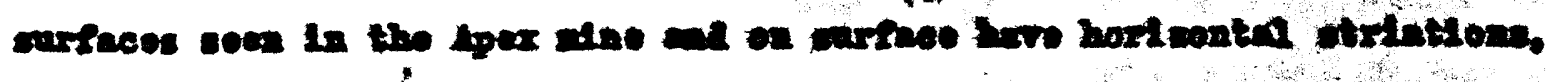

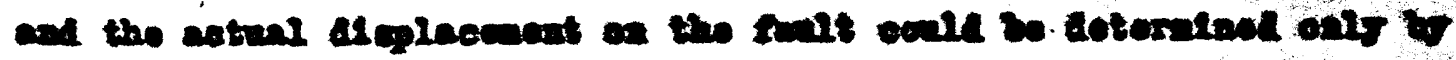

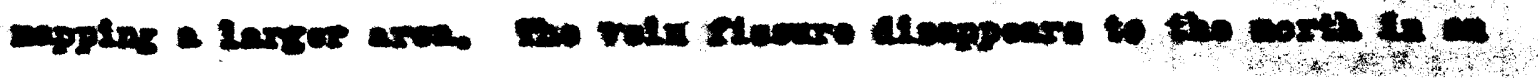




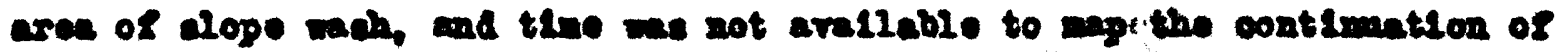
tho therare to the north. In parallal steware 350 soot to the west

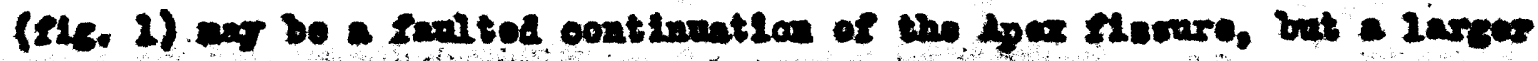

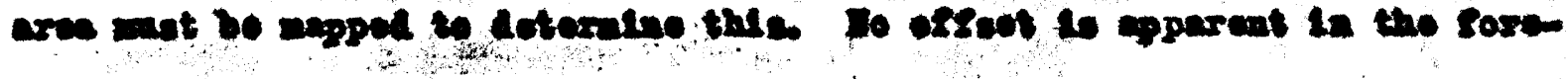

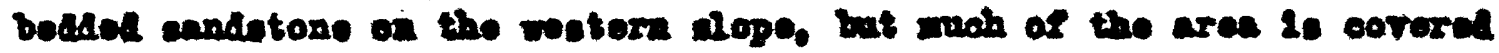

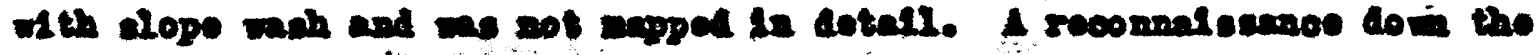

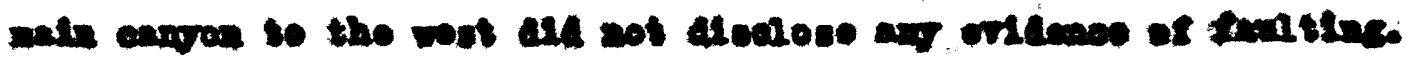

\section{Depostso}

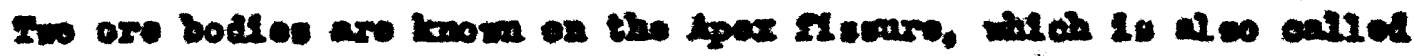

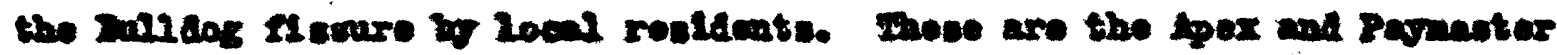

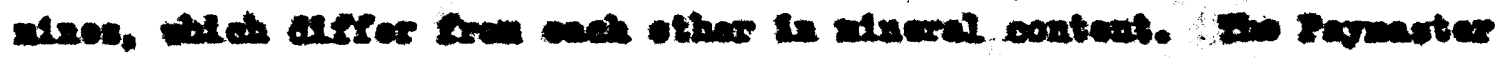

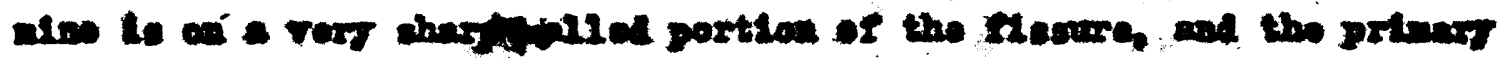

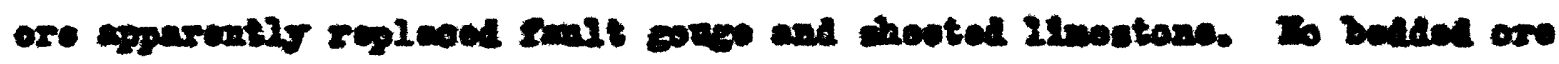

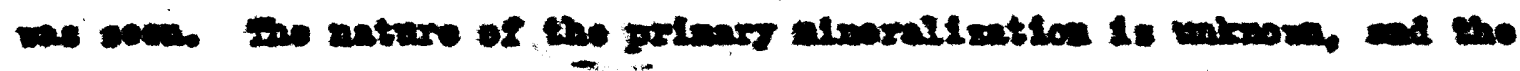

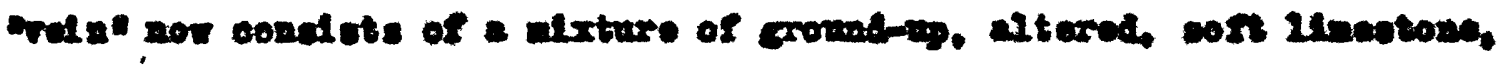

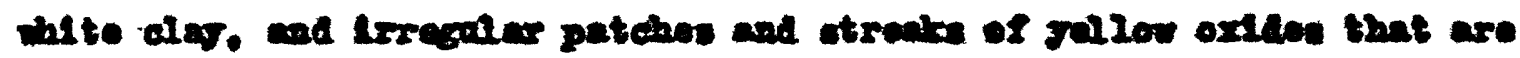

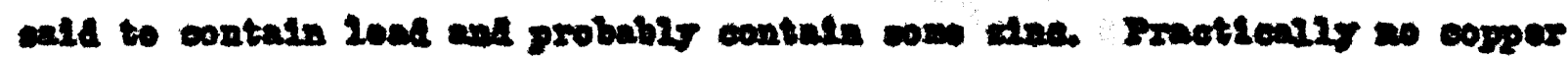
1. provant.

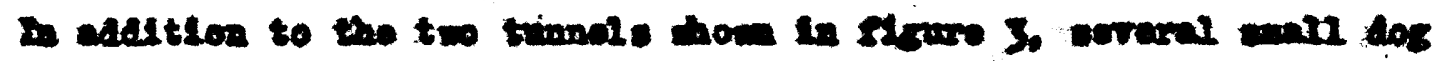

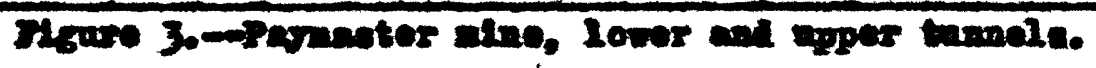

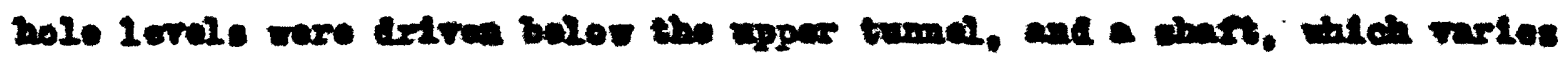

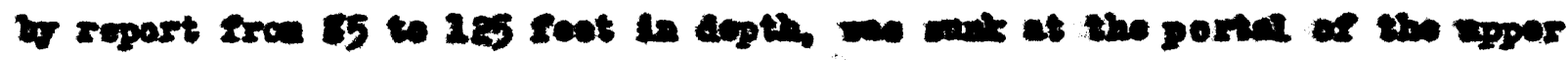

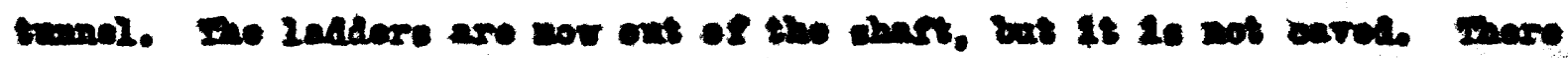

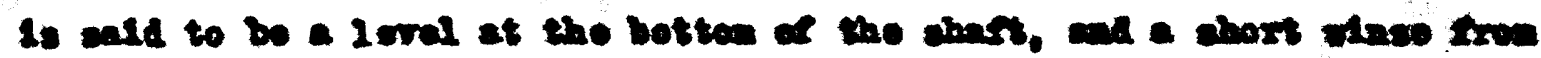

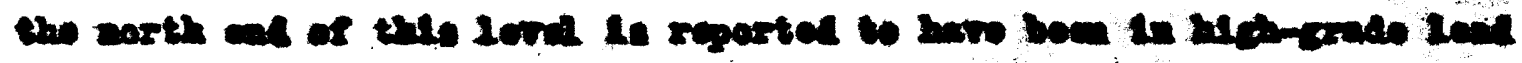

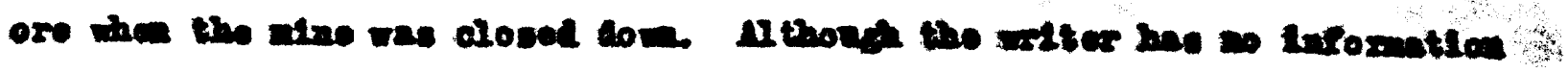


on tho credo of ore in the Papaster alno, tho mino do on a strong

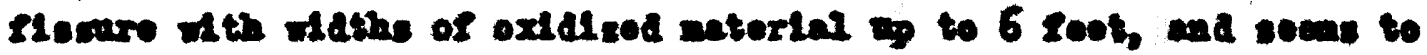

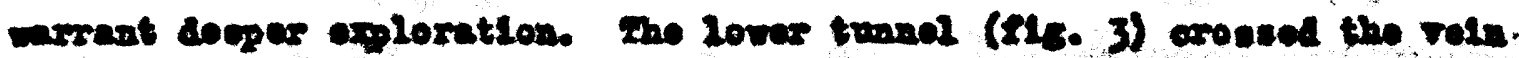

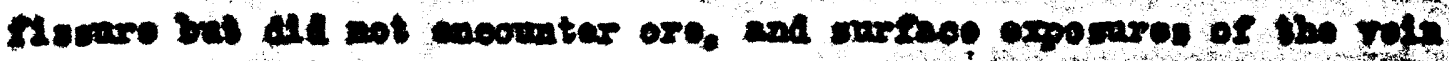

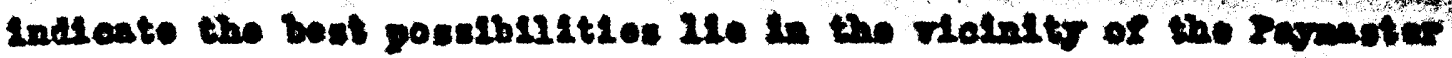
abaft and the ares of atrops alseratlon porthreat of the man.

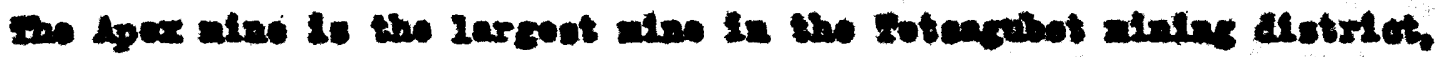

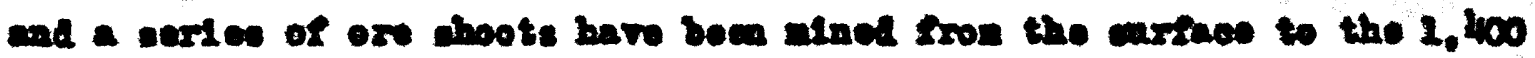

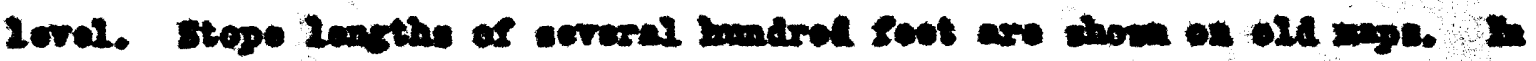

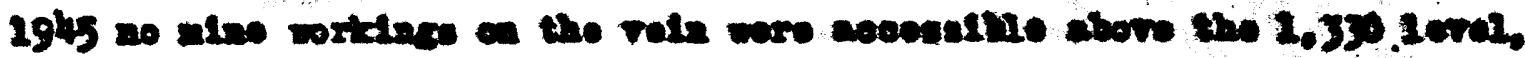

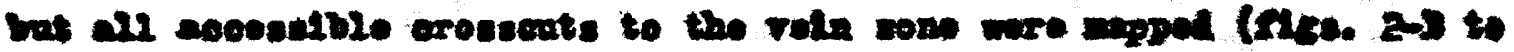

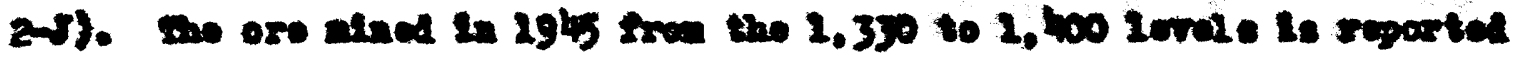

Insaree $2-3-2-3 .-4 p a x$ also

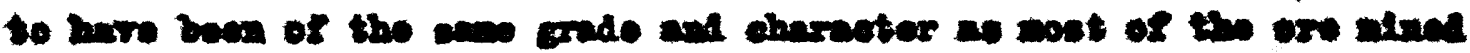
ebore these 1 errele.

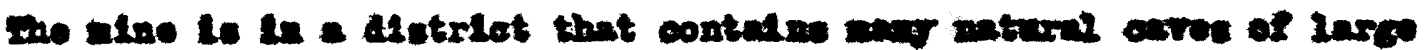

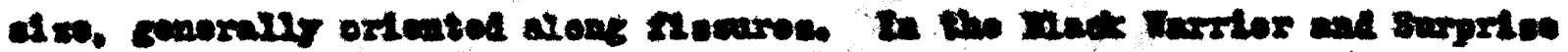

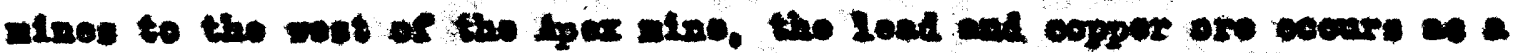

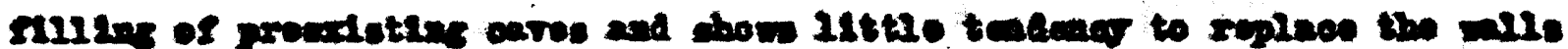

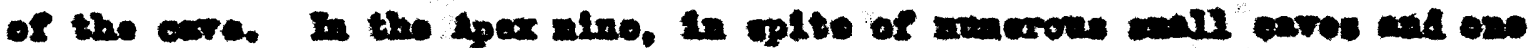

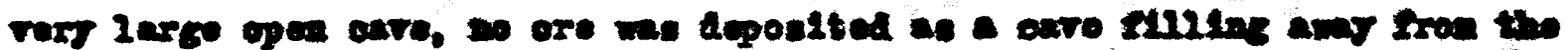

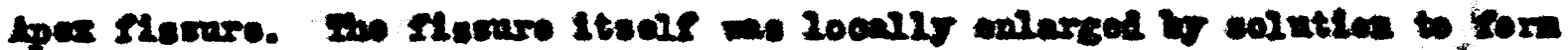

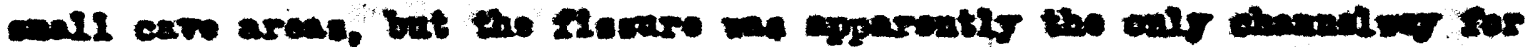

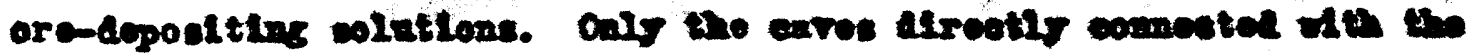
Sterere aro exe bearlec. 
The ore constete of alachlte, armedte, and other copper oxides in

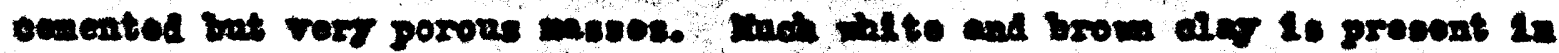

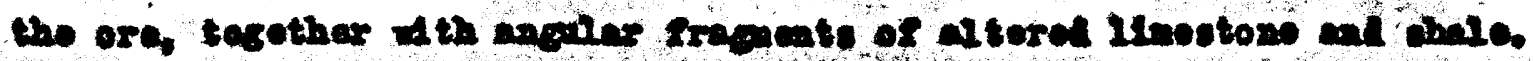

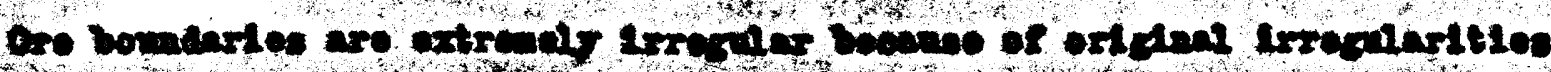

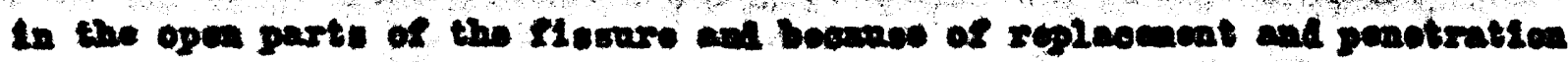

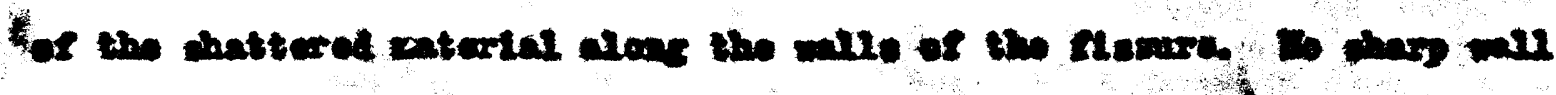

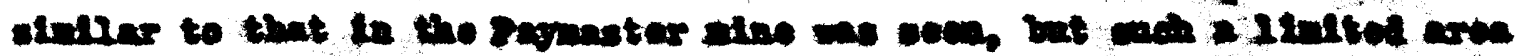

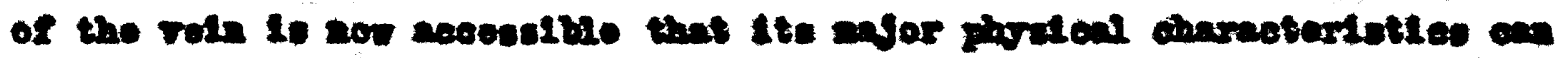
onto bo gonece mep.

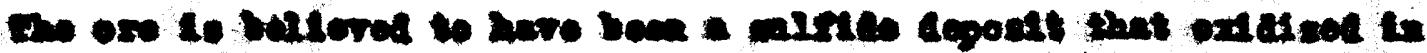

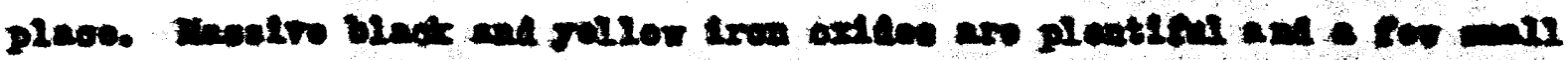

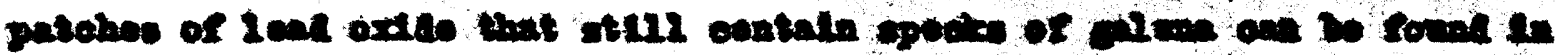

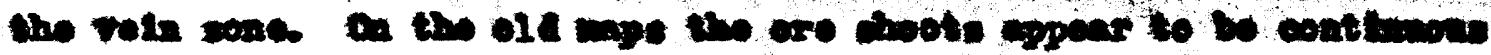

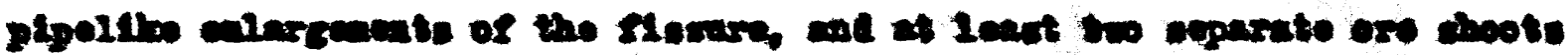
were alned sar a whor of lovels.

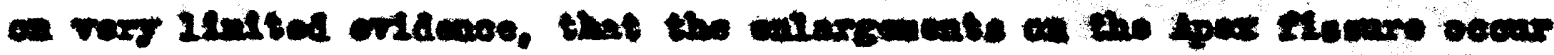

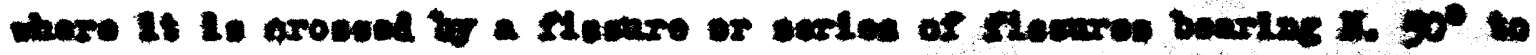

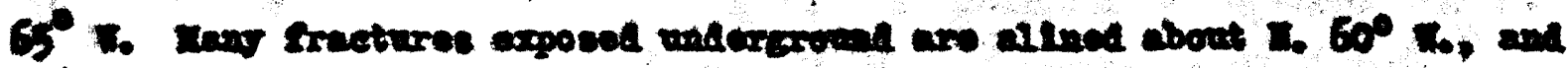

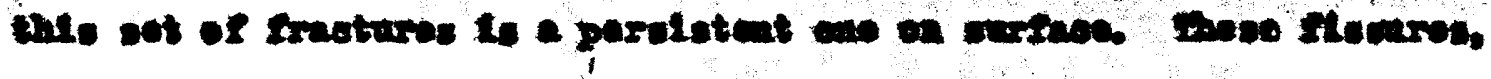

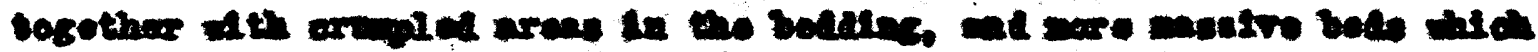

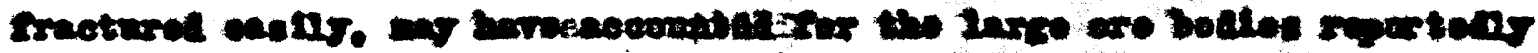

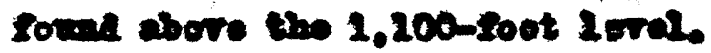

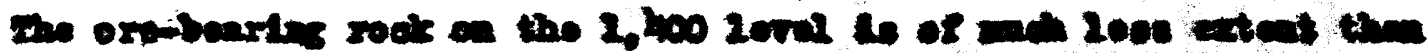

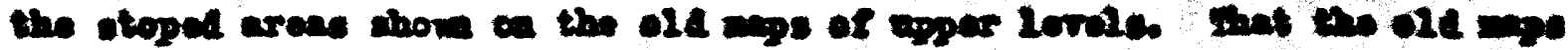

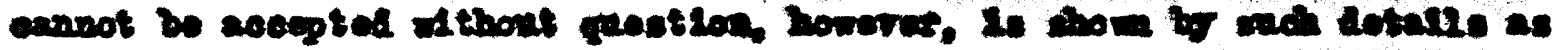

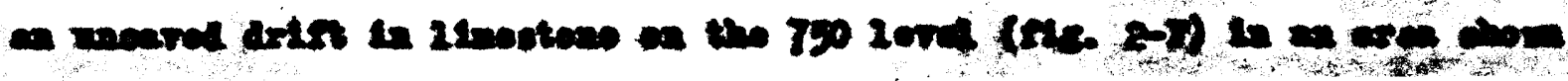




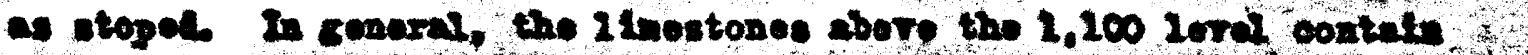

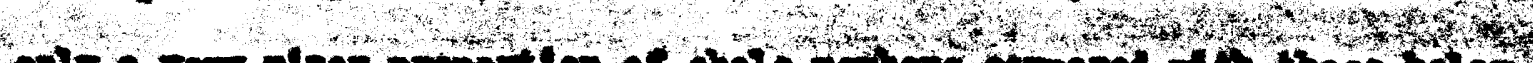

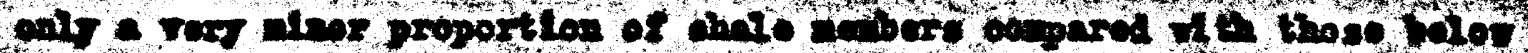

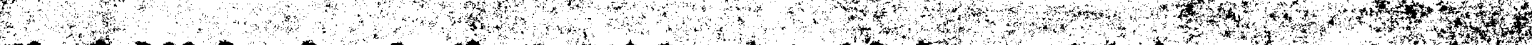

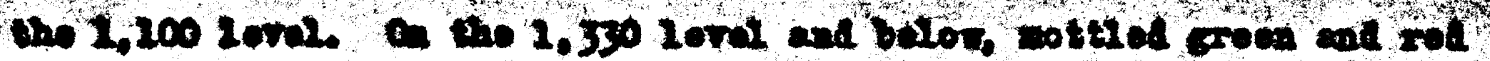

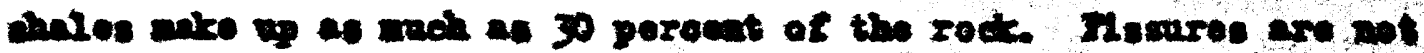

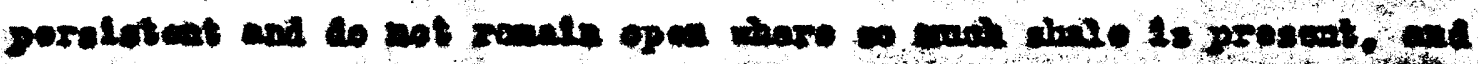
atc.

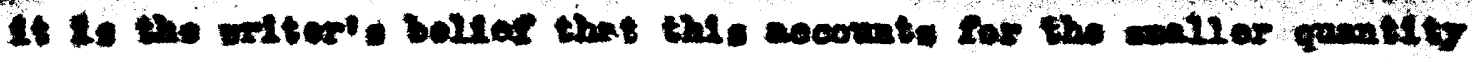

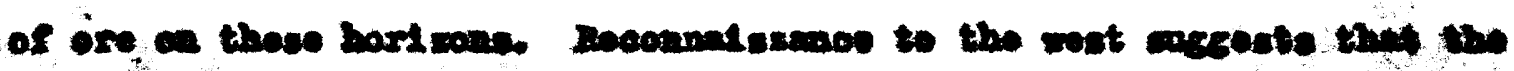

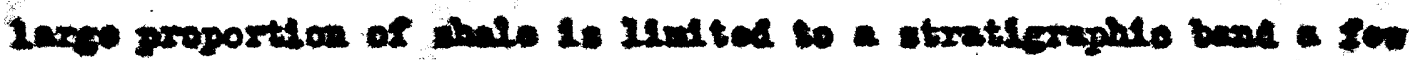

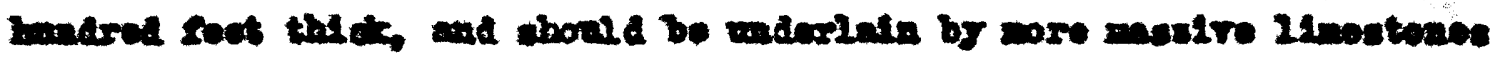

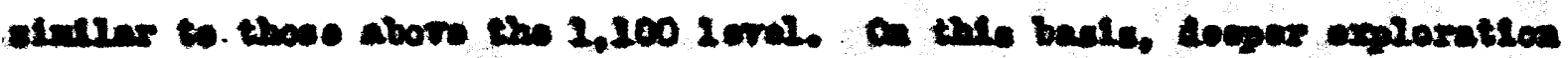

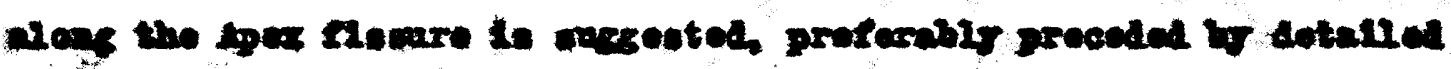

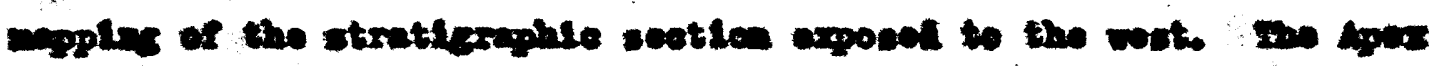

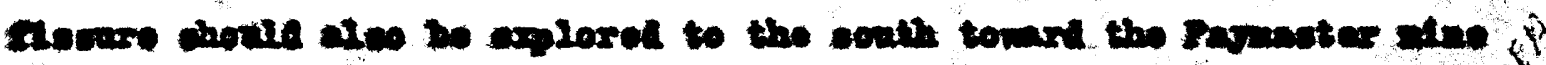

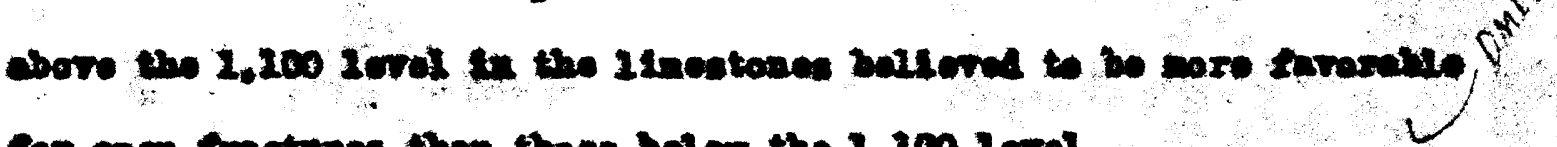

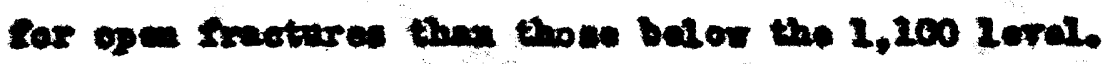

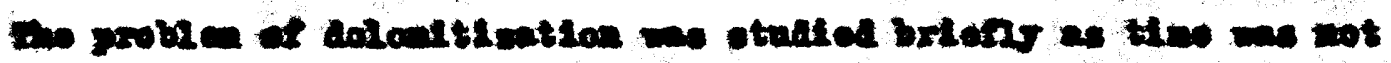

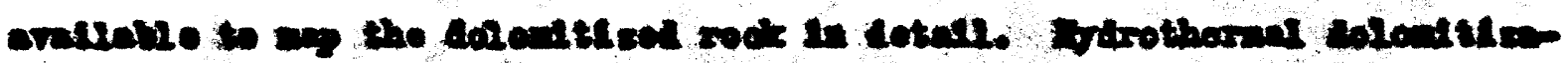

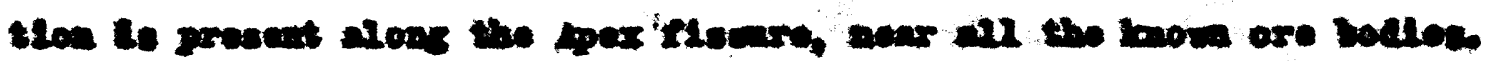

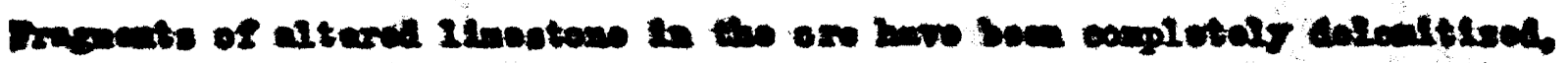

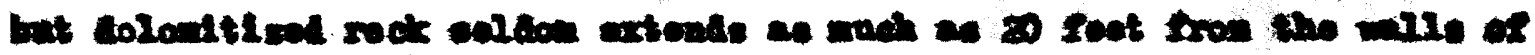

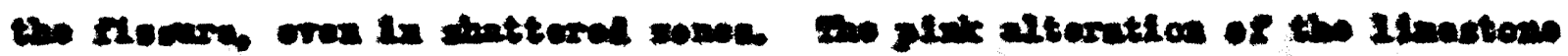

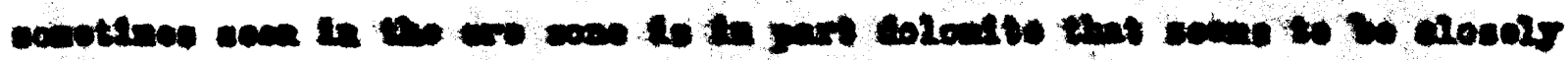

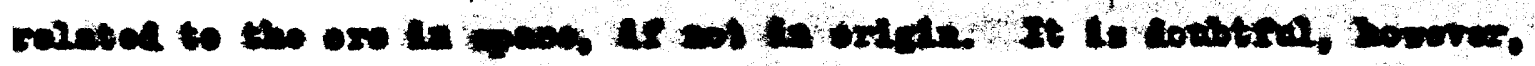

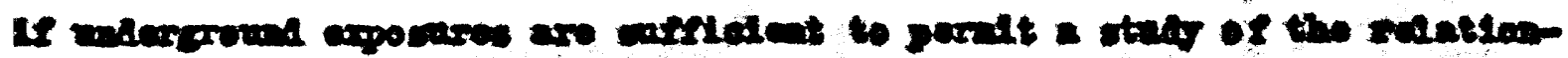

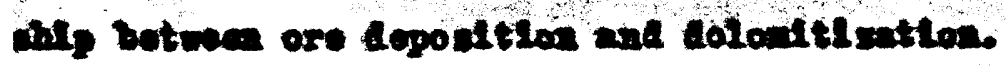

